\title{
Desertesejo: Partilha e simulação
}

Fábio Oliveira Nunes

\section{Universidade Estadual de Campinas}

\section{Resumo}

Trata-se de uma reflexão em torno dos conceitos de partilha e simulação em Realidade Virtual, a partir da abordagem do trabalho Desertesejo (2000/2002), ambiente virtual multiusuário disponibilizado na Internet, do artista brasileiro Gilbertto Prado.

Palavras-chave: ambientes multiusuário, arte na rede, arte telemática, web arte.

$$
\begin{array}{r}
\text { "Bem-vindo ao deserto do real". } \\
\text { Morpheus, personagem do filme Matrix, } \\
\text { parafraseando Jean Baudrillard. }
\end{array}
$$

Ano 1999. Neo é levado pela recepcionista do oráculo até uma sala de estar onde estão várias crianças. Ela pede para que ele aguarde um pouco. Na sua frente, um pequeno garoto com longas vestes orientais e cabelos ralos entorta a haste de uma colher somente fixando seu olhar no objeto.

Neo, surpreso, admira o que vê. O garoto, por sua vez, retorna a colher ao seu ponto original e a entrega silenciosamente a Neo. Ele pega a colher, a examina e continua perplexo. O menino, transmitindo a tranqüilidade de um monge, diz:

- Não tente entortar a colher. É impossível. Em vez disso, apenas tente ver a verdade.

- Que verdade? - interroga Neo.

- Que a colher não existe.

- A colher não existe? - Neo examinava a colher ainda mais minuciosamente.

- Você verá que não é a colher que entorta. É você mesmo. 
O trecho acima é uma cena do filme Matrix ${ }^{1}$, considerado por muitos como um dos pontos altos da ficção científica do fim dos anos 90, onde é narrada a ascensão de Neo, um hacker que descobre que a vida que conhece no século 20 é uma simulação imposta por máquinas digitais intelectualmente superiores. $\mathrm{Na}$ verdade, ele encontra-se no século 22 e as máquinas que dominam a terra, utilizam-se de uma fantástica realidade virtual para manter os seres humanos - fonte de energia bioelétrica - quietos e ocupados em suas mentes, enquanto passam toda sua existência em câmaras, nutridos por restos liquefeitos de seus irmãos ${ }^{2}$.

A substituição da realidade na qual nossos corpos estão inseridos por um espaço sintético de realidade, um espaço de domínio mental - no qual psicológica e perceptivamente imergimos - povoa o imaginário humano. No universo dos games $^{3}$, o indivíduo ali participante é muitas vezes, representado na tela por um ator eletrônico, personificandose enquanto parte do universo eletronicamente proposto. Transfere-se enquanto sujeito. O foco de atenção parece favorecer o distanciamento da realidade real - num estado de suspensão entre duas realidades, uma psicológica, outra física.

Essa imersão certamente não está ligada somente a uma questão de atenção e foco de situação e sim, também aos nossos processos sensoriais, dos nossos sentidos físicos - visão, audição, tato e olfato - mas também a sentidos induzidos por estes na relação com o mundo externo, como o senso de direção e profundidade, por exemplo. E ao mesmo tempo, a atenção é um processo muito pessoal - assim como o poder de concentração - podendo ser destituída facilmente por estímulos externos do mundo real. Para lidar com essas questões, surgem vários dispositivos - tais como óculos, fones, capacetes - que possibilitam uma imersão que não depende somente do foco do participante, num percurso que busca o preenchimento dos nossos sentidos, conforme KERCKHOVE (1997:51):

Nas telas hiper e multimídias, a combinatória plurissensorial que naturalmente nosso cérebro pratica para construir algumas de suas imagens tornou-se possível fora do próprio cérebro. 
(...) A transfusão de toda nossa sensorialidade das modalidades analógicas às modalidades digitais pela numeralização elimina o obstáculo dos sentidos. Cada sentido torna-se traduzível em termos de cada um dos outros. A moda das multimídias reflete, pois, nosso desejo profundo de projetar nos nossos sentidos exteriorizados uma função cognitiva integrada. É o sonho da atividade artística.

Por este caminho, um dos antecessores da realidade virtual é - Sensorama. Numa tentativa de múltiplas sensações, Morton Heilig desenvolve em 1962 uma espécie de cinema dos sentidos onde o indivíduo tinha a sua disposição uma tela com visão estereoscópica ${ }^{4}$, cheiros, ventiladores de ar, som e uma cadeira que tremia, tudo isso conforme $\circ$ andamento da narrativa acompanhada - um passeio pelo bairro do Brooklyn em Nova Iorque. Alguns dos elementos desse advento modernizados certamente - ainda permanecem nos simuladores e cinemas em terceira dimensão, presentes em centros de entretenimento.

Mas certamente, a discussão sobre a realidade virtual ${ }^{5}$ não se resume simplesmente numa aglutinação sensorial, ainda que sua existência diretamente dependa do fator perceptivo. Numa breve observação, vê-se que seus antecessores como a fotografia e o cinema, dependem diretamente do mundo real para existir, bem como a televisão que ainda também parte de princípios de representação do século XIX (COUCHOT, 1993:41). Mesmo a arte moderna, que se livra para representação para a presentificação, agora apresentando a si mesma como presente, permanece absorta no domínio do real. Na Realidade Virtual, a simulação abre espaço para a reinvenção, para a criação de modelos e situações que não cabem no âmbito da realidade física pela sua própria essência, ainda que alimentada pela nossa vivência no plano físico.

O trabalho Desertesejo6 (2000/2002) do artista brasileiro Gilbertto Prado, ambiente virtual criado em VRML (Virtual Reality Modeling Language - Linguagem de modelação de realidade virtual) e disponibilizado na Internet, transita por estas questões. É sobre esse trabalho que vamos tecer considerações mais adiante. 


\subsection{Redes telemáticas e participação}

Gilbertto Prado é um dos artistas brasileiros mais atuantes no campo da arte mídia: sua tese de doutorado defendida em 1994 na Universidade de Paris I, Panthéon Sorbonne, que teve por tema as experimentações artísticas telemáticas, é uma das primeiras realizadas abordando essas questões. Participa do grupo Art-Réseaux, Paris e em diversos eventos - exposições, colóquios - realizados no exterior. É professor do departamento de Artes Plásticas da ECA/USP.

Sua trajetória confunde-se com o próprio percurso das artes ligadas aos meios de comunicação: já realizou trabalhos de arte postal, fax-arte, redes computacionais pré-internet, sites na rede e por último, realidade virtual. Sua postura, investigativa nos novos meios é, em certa medida, demonstrada por projetos de pesquisa e reflexão teórica como o site wAwRwT ${ }^{7}$, que visa a observar espaços de arte na rede Internet.

Um dos seus principais trabalhos utilizando redes computacionais é Moone, La Face Cachée de la Lunne (1992), apresentado no Eletronic Cafe ${ }^{8}$ em Paris e em Kassel (IX Documenta), na Alemanha. Neste trabalho, através de uma linha de conexão via RSDI9 entre as duas cidades, o artista disponibiliza um espaço de criação coletiva, no qual é possível produzir uma imagem em conjunto com parceiros distantes - e desconhecidos - em tempo real. Assim, através desse processo, a mesma imagem aparece simultaneamente em diferentes monitores, ao passo que cada participante pode, em tempo real, acompanhar, interagir, modificar as alterações de outro ou mesmo sobrepor com os elementos de sua escolha. Trata-se então de estabelecer um espaço de criação coletiva, cujo trabalho apresenta-se mais como um canal de processo e receptáculo dessas intervenções, onde a ação do participante é necessária para que a poética do trabalho se efetive. Sobre as possibilidades de diálogo participativo em redes, PRADO (1997b:43) discorre:

Transposto ao plano da prática, os intercâmbios levam em consideração as relações entre a validade primeira do projeto e a coerência desenvolvida pela nossa participação crítica, 
entre a unidade que inaugura o projeto e a pluralidade possível que venha a surgir. Em ocorrência, nós temos um trajeto que não tinha jamais se estabelecido anteriormente, que não se estanca num ponto determinado, numa perspectiva voluntariamente limitada do espaço artístico-participativo, mas num mundo perpetuamente nascente.

Ainda que anterior à Internet, estava consumada a relação de arte em rede computacional em Moone, numa escala de contato simultâneo que ainda nos impressiona quando nos deparamos com algo semelhante na web. Um exemplo, que se aproxima em modus operanti e resultados, é o site de web arte open studiolo, do artista Andy Deck, onde se disponibiliza um canal no qual os usuários, quando simultaneamente conectados, podem desenhar coletivamente, acompanhar e sobrepor garatujas. Muito posterior ao trabalho realizado em RDSI, reforça o caráter preambular das questões levantadas por Prado.

Em ambos os casos, temos uma coletividade que se resolve no campo do virtual, que se encontra, interage e desfaz-se num espaço comum inserido na ordem das possibilidades oferecidas em cada um dos canais. Assim como nos conhecidos chats da rede Internet, nos quais se pode estabelecer contato por meio de texto e como em softwares de comunidades virtuais como o Active Worlds 11 , onde além do contato textual há também a projeção do indivíduo em terceira dimensão sob a forma de um avatar - termo advindo do hindu, que significa a encarnação de Deus - que se locomove, aproxima e distancia de seus semelhantes simultaneamente conectados.

Aliás, mundos como Active Worlds, nos interessam também pela junção da comunicação simultânea entre os usuários - ambiente multiusuário - e tridimensionalidade espacial. Um espaço de realidade virtual compartilhado. Através do programa pode se ter acesso a centenas de mundos virtuais que são construídos pelos próprios associados, a maioria deles, com temas diversos, como cenários cinematográficos, referenciais a períodos da história da arte ou a cidades fisicamente existentes. A idéia de tradução literal da cidade real, com suas ruas, prédios, trânsito e transeuntes é muito recorrente nos espaços disponibilizados. Reverencia-se o conhecido, para adentrar o desconhecido. 


\subsection{Realidade Virtual}

A Realidade Virtual (RV) surge num cenário militar: suas primeiras utilizações estão relacionadas aos simuladores de vôo que ensinam aos pilotos como voar em determinadas situações. Pesquisas desenvolvidas pelo exército americano, durante a $2^{a}$ guerra mundial, indicavam que quase a totalidade de acidentes concentrava-se em pilotos com cinco ou menos missões de combate, daí a necessidade de um sistema que, em terra, simulasse situações reais.

Os primeiros simuladores computacionais de vôo utilizavam-se de um vídeo-capacete onde era possível obter uma visão estereoscópica e pela utilização de sensores de posição devidamente espalhados pelo corpo, pode-se dar uma sensação de correlação muscular. Em 1989, o Departamento de Defesa Norte-Americano (DoD) lança Simnet (Simulator Network), uma rede experimental baseada em microcomputadores que permitiu ao pessoal militar praticar operações de combate em sistemas de treinamento interativo de tempo real. o simnet foi utilizado pelos soldados americanos para a Guerra do Golfo, em 1991.

Ao lado das utilizações militares, artistas como Myron Krueger estabelecem experimentações que se aproximam da Realidade Virtual. Krueger desenvolve em 1969, uma instalação que ele denominou como realidade artificial chamada Videoplace na qual o visitante pode interagir com elementos sintéticos sobre uma tela. A imagem da pessoa é projetada e é possível interferir em formas e objetos em movimento. No fim dos anos 80, surgem os primeiros kits de realidade virtual em 3D que permitem uma completa imersão nos espaços sintéticos. Tom Zimmerman, procurando criar um dispositivo de simulação de instrumento musical, desenvolve uma data glove12 que possibilita manipular, tomar e até construir objetos virtuais no uso conjunto de um capacete especial desenvolvido por Jaron Leiner13. Assim, alguns especialistas preferem definir duas modalidades de RV: a realidade virtual não-imersiva, acessível através de telas de computadores e a realidade virtual imersiva, acessível através de dispositivos especiais (figura 23) como capacetes e CAVEs ${ }^{14}$. 
É certo que a presença de Realidade Virtual a qual estamos mais acostumados no nosso dia - a - dia é através dos games não exatamente jogando, mas se torna cada vez mais difícil não notá-los - que perduram por gerações, desde o advento do Atari15. Porém, as utilizações da RV se expandem para outros campos do conhecimento como a medicina, as ciências exatas, como a astronomia e a física e na educação. Muitos avanços em Realidade Virtual têm sido alcançados pela Agência Espacial Americana - a NASA. Com a popularização das redes telemáticas ${ }^{16}$, passa a ser possível não só imergir isoladamente como também interagir em tempo real com outros indivíduos ao mesmo tempo, num mesmo espaço. Para tanto, a WWW17 - a interface gráfica da rede - teve um papel fundamental.

\subsubsection{Realidade Virtual via Internet}

Através da acessibilidade da WWW e das facilidades da linguagem HTML ${ }^{18}$, a rede Internet no fim dos anos 90 caminha para a sua ascensão: a onipresença em torno do globo, ramificada, autônoma, descentralizada, um rizoma19 pulsante povoado por milhões de indivíduos e seus web sites. Mas os conteúdos da rede ainda são majoritariamente bidimensionais: muitas páginas ainda permanecem no paradigma impresso (ou no máximo, aventurando-se em algum conteúdo multimídia) embora já existam diversas ferramentas de criação de espaços navegáveis e exploratórios em terceira dimensão, acessíveis ao usuário leigo diante de especificidades técnicas.

$\mathrm{Na}$ Internet, a apresentação de conteúdos tridimensionais se dá basicamente através da VRML - o equivalente da HTML para ambientes em terceira dimensão, já que também se resume basicamente em um documento de texto - que surge em 1995, com - surgimento da versão 1.0. Esta versão permitia o desenvolvimento de cenas estáticas, sem animação. No ano seguinte, surge uma versão sucessora: 2.0 que, por sua vez, teve sua sintaxe redefinida e passou a aceitar animações, imagens de background, efeitos de névoa e outras extensões. Em 1997, a VRML obteve outras especificações e passou a ter uma nova denominação: VRML 97. A maioria dos browsers 20 (navegadores) para visualização de VRML é compatível com os dois últimos formatos. 
Assim como a HTML, a VRML possibilita a sua criação através do desvendamento de seu código fonte, com tags (comandos) tão simples quanto sua versão bidimensional. Porém, existem editores gráficos que possibilitam um desenvolvimento mais intuitivo a partir da utilização de formas básicas e linhas. Por ser um arquivo textual, possibilita a criação de amplos espaços virtuais, acessíveis a computadores com baixa largura de banda, via conexão discada, devido ao reduzido tamanho do arquivo. Ao mesmo tempo, sua navegação até requer alguma habilidade, mas apresenta-se extremamente simples, na maioria dos navegadores.

As utilizações artísticas em VRML estão efetivamente presentes na produção brasileira de web arte: além de já ter sido utilizada por artistas como Silvia Laurentiz e Lúcia Leão, é amplamente utilizada por suzete Venturelli e Tânia Fraga, ambas pesquisadoras do Instituto de Artes da Universidade de Brasília (UnB). Na Internet, é possível encontrar diversos trabalhos artísticos desenvolvidos em VRML: o Festival Web3D Art 21 , por exemplo, específico em trabalhos exploratórios em terceira dimensão, possibilita o acesso a diversos trabalhos. Após este brevíssimo percurso sobre a Realidade Virtual e algumas de suas utilizações, vamos nos voltar agora a Desertesejo.

\subsection{Desertesejo}

Desertesejo (Deserto + Desejo) é, segundo o seu próprio autor "um ambiente virtual interativo multiusuário para Web que explora poeticamente a extensão geográfica, rupturas temporais, a solidão, a reinvenção constante e a proliferação de pontos de encontro e partilha" (PRADO, 2003a). Desenvolvido em tecnologia VRML 22 através do Programa Rumos do Itaú Cultural, São Paulo, o projeto contou com uma equipe de especialistas em modelação e design, que seguiam as diretrizes dadas pelo artista. Foi possível dispor de profissionais gabaritados em conhecimentos específicos para a execução de um objetivo comum. O resultado de mais de um ano de trabalho foi apresentado em 2000 pelo Itaú Cultural e mais tarde, em 2002, na 25a Bienal de São Paulo, Núcleo Net Arte Brasil, além de outros eventos como 0 9 Prix Möbius International des Multimédias - Pequim, China, 2001. 
O trabalho é constituído de três ambientes interligados entre si: o primeiro é chamado de Ouro, onde existe a simulação de um extenso deserto onde o individuo solitariamente navega; o segundo espaço é Viridis, espaço circular azul onde é possível perceber a entrada de outros visitantes - através de uma sala que apresenta imagens de céus - mas não há qualquer contato; já o terceiro espaço, chamado Plumas, trata-se de uma simulação de deserto dividido em três situações diferentes de apresentação - similar ao ambiente Ouro, monocromática e line-art - no qual se torna possível o contato entre os visitantes.

Pensando na metáfora do deserto, discorre DOMINGUES $(2002: 38)$ :

o cenário contemporâneo é um deserto de paixões e um excitante mundo virtual das memórias eletrônicas. Nossa consciência experiencia uma ruptura do excesso numa situação dialética: o cheio e o vazio simultaneamente. Eu estou retomando a metáfora contemporânea do deserto 23 que resulta da morte das ideologias neste mundo em que as paixões políticas, públicas e privadas perderam sua força dramática. Mas, no deserto, nós também temos experiências iniciáticas. Na mesma direção, ao conectar mundos virtuais, vivemos o vazio do real e as múltiplas opções de dados.

Já aos olhos de Edmond JABÈs (1989:107-108), renomado escritor franco-egípcio, outras recorrências da figura do deserto:

Não se pode falar do deserto como de um lugar; pois ele é, também, um não lugar; o não-lugar de um lugar ou o lugar de um não-lugar. Não se pode pretender que o deserto seja uma distância, porque ele é, ao mesmo tempo, real distância e não-distância absoluta por causa de sua ausência de marcas. Ele tem, como limites, os quatro horizontes, sendo o que os liga e os separa. Ele é sua própria separação onde ele se torna lugar aberto; abertura do lugar. Não se pode pretender que o deserto seja o vazio, o nada. Não se pode, tampouco, pretender que ele seja o término, uma vez que ele é, igualmente, o começo. 
É cativante imaginar o deserto como um silencioso estado de suspensão da existência, território sem territorialidade, como é a própria rede Internet.

Voltando ao trabalho de Prado, temos então, antes de entrar no primeiro ambiente - o único entre os três em que a passagem é indispensável para ver outro ambiente 24 - uma situação na qual o visitante encontra-se dentro de uma caverna que possui uma fenda luminosa de onde caem algumas pedras. Nesta escura caverna, o único foco de luz provém do exterior, por meio da fenda, iluminando um pequeno espaço no chão, onde estão as pedras. Cada pedra é clicável e direciona para um lugar diferente do ambiente Ouro. Este é o momento de reclusão, o espaço primeiro das escolhas de destino, bifurcação de caminhos.

Essa situação pode se relacionar com a conhecida alegoria da caverna, colocada por Platão no livro VII, em "A República". É uma leitura possível: a caverna por Platão espelha a própria prática filosófica, sua busca em torno da verdade, do conhecimento, da verdadeira realidade e o posterior retorno ao mundo das trevas, da obscuridade, da aceitação das coisas conforme são vistas. A metáfora da luz possui uma múltipla dimensão, traduzindo a ascensão tanto como filosófica quanto científica ou política - contexto de "A República". observando mais detalhadamente:

A alegoria da caverna dramatiza a ascese do conhecimento (...). Descreve um prisioneiro que contempla, no fundo de uma caverna, os reflexos de simulacros que - sem que ele possa ver - são transportados à frente de um fogo artificial. Como sempre viu essa projeção de artefatos, toma-os por realidade e permanece iludido. A situação desmonta-se e inverte-se desde que o prisioneiro se liberta: reconhece o engano em que permanecera, descobre a "encenação" que até então o enganara e, depois de galgar a rampa que conduz à saída da caverna, pode lá fora começar a contemplar a verdadeira realidade. Aos poucos, ele, primeiro através de reflexos - como o do céu estrelado refletido na superfície das águas tranqüilas - até finalmente ter condições para olhar diretamente o sol, fonte de toda luz e de toda realidade. (FLORIDO, 1999:26) 
Em ambas as situações, é a partir da caverna que se dará o acesso a um novo patamar de realidade. Além disso, o ritual iniciatório frente à luz, pode se associar ao caminho colocado em Desertesejo: Ouro, a navegação solitária, é um nível obrigatório para os outros dois momentos. É preciso acostumar-se a esta nova realidade assim como os olhos demoram a adaptar a luz.

Ao clicar, então, em uma das pedras, somos transportados para o primeiro ambiente, o Ouro. O visitante poderá imergir no espaço sob a ótica de um dos três animais: serpente, águia e onça. Cada animal terá uma perspectiva e velocidade diferente ao navegar o espaço. E ainda, o visitante irá surgir em uma localização diferente, dependendo da pedra escolhida na caverna. Além da extrema qualidade dos gráficos - formas e respectivas texturas - o ambiente chama a atenção pela grandiosidade de sua extensão: o deserto colocado por Prado perde-se no horizonte, nas suas reentrâncias e montanhas. E por conta dessa proporção, alcança-se um patamar poético, onde solidão e desamparo se encontram em um percurso em suspensão, sem rumo definido.

Em proximidade, como possuidor desse mesmo percurso indefinido e solitário, podemos citar o pioneiro trabalho Legibles Cities (1989-1992) do australiano Jeffrey Shaw. O artista disponibiliza num espaço expositivo real, uma bicicleta equipada com sensores de movimento - no pedal e guidom - e projeção de um espaço virtual em 3D. Através destes dispositivos, o participante irá "pedalar" pelo espaço virtual - este criado em semelhança aos mapas de Nova Iorque e outras cidades - todo ele composto de textos poéticos no lugar de edifícios ou casas. Assim como em Desertesejo não há um objetivo ou caminho explicitamente colocado, a despeito do universo dos games, em que fases e tarefas inclinam para um objeto bem definido. Coloca-se o espaço à mercê da exploração de suas territorialidades.

Voltando à caverna, a pedra clicada será protagonista de um rito de passagem proposto pelo artista: em determinados momentos do ambiente será possível encontrar um monte de pedras em formato piramidal onde é possível "colocar" a pedra antes clicada - e metaforicamente, carregada pelo visitante 
até este momento. Sobre o entendimento deste rito, discorre PRADO (2003a):

\begin{abstract}
Durante a realização deste trabalho eu fui andar em alguns desertos como o de Atacama no Chile e ainda regiões áridas e arenosas como os lençóis maranhenses entre outros locais - só lembrando que este espaço que nós vemos é onírico e construído e não réplica de um espaço existente, embora seja marcado de alusões e referências, decalcado pelas sensações, estórias e percursos. Mas, quando eu estava no Chile, andando no meio do deserto, eu percebi alguns desses montinhos de pedras espalhados naquele vasto espaço e me perguntava, qual seria a intenção desses pequenos montes com essas pedras empilhadas e colocadas acerca dos caminhos e trilhas na areia, será que estavam aí para guiar alguém? Para que se tivesse alguma referência, pontos de reparo nesses vastos espaços? Até que perguntei para um nativo, mas afinal de contas porque que empilhavam essas pedras nesses locais, e ele respondeu que eram lugares especiais. Quando você sai da sua casa você pega de perto de onde você vive uma pedra e a carrega até o momento em que você chega em algum lugar, aonde você acha que aquele é o local onde a sua pedra deve ser depositada e então você a dispõe junto com as outras. É uma espécie de oferenda. Pensando nisso, transformei esses montículos que encontramos nos caminhos do Desertesejo, em marcadores de presença (contador).
\end{abstract}

Mais do que representações numéricas de passagem, essas marcas denotam um consenso da coletividade, como lugar de intersecção de consciências.

Além dos montes de pedra, o visitante irá também encontrar portais em formas cilíndricas, que darão acesso aos outros dois ambientes de Desertesejo. Cada cilindro é portal para um ambiente. Assim, clicando em um deles, podemos seguir para o segundo momento: Viridis.

Viridis25 é o espaço das referências geográficas, terrestres. É intermediário entre os outros dois ambientes: estar só e perceber-se acompanhado. Por meio de uma das salas do ambiente é possível visualizar a entrada de outros participantes no mesmo espaço: vê-se vários céus fotografados e cada alteração destes indica que um novo visitante entra 
no espaço através da alteração dos céus fotograficamente apresentados. Conforme a hora no lugar de origem do novo visitante, o céu se apresentará como noite ou dia, amanhecer ou entardecer 26 .

Ao contrário de Ouro, Viridis é muito mais contido em sua expansão, apresenta-se como um espaço onírico, em vários tons de azul, referenciando diretamente um trabalho anterior do artista: 9/4 Fragmentos de Azul (1997), apresentado inicialmente 27 no Itaú Cultural, em São Paulo, que consistia em uma instalação multimídia com diversos monitores de telas sensíveis ao toque dos visitantes (figura 30). Nas telas, pelas pontas de seus dedos, os participantes alteravam a composição das imagens, num "azul eletrônico" comum a todas elas. Igualmente referenciando a Yves Klein, o artista Stephan Barron propõe situações semelhantes em Le Bleu du Ciel28 (1992/1993). Neste trabalho - instalação - o visitante pode comparar o céu onde ele se encontra, capturado através de uma câmera e ao mesmo tempo, visualizar o céu de um espaço fisicamente distante e ainda, num terceiro momento, ver a somatória visual dos dois céus sobrepostos criando um céu de cor média, que não existe em lugar algum. Muito parecido é Le Jour et la nuit ${ }^{29}$ (1995) em que o artista disponibiliza dois computadores que capturam imagens do céu, um no Brasil e outro na Austrália, para a justaposição e mistura dos céus de ambos . Assim como a sala dos céus de Desertesejo, as instalações de Barron devem contribuir para a tomada de consciência pelo espectador da interação do local e do planetário e das responsabilidades implicadas pelo caráter ubiqüitário da tecnologia (COUCHOT, 2003:244).

O ambiente Plumas, o último dos três momentos, é quando se efetiva o contato com o outro. Este espaço inicialmente se parece muito com o deserto de Ouro, sendo, porém, mais onírico e distante de uma aproximação mais íntima com o real, apresentando diferentes situações: com texturas e cores próximas de Ouro, monocromática ou ainda, line-art - deixando a estrutura à mostra, onde não vemos chão, embora sabemos que lá ele está. Porém, a maior diferença em relação aos outros ambientes é certamente sua propriedade multiusuário - 50 visitantes podem conectar-se e conversar via texto 
simultaneamente, em tempo real, enxergando uns aos outros através de seus avatares.

Aí se consome outra relação: o contato. Na web, esta prática é difundida nas salas de bate-papo virtual (chats), populares desde o advento do IRC30 (Internet Relax Chat), em 1988, até as salas de bate-papo nos grandes sites portais31 que aglutinam usuários das mais variadas idades e interesses. Na cultura contemporânea do solipsismo, as pessoas parecem procurar preencher o vazio das suas relações sociais, cada vez mais inacessíveis pela verticalização das moradias, da falta de laços pessoais nas grandes metrópoles, da desconfiança no outro. E esse vazio - como já foi dito - é possível de ser simbolizado pela imagem do deserto.

Voltando-se a Plumas, disponibiliza-se um canal de troca, partilha e relações:

O artista, no caso, potencializa uma situação onde as pessoas vão entrar e vão poder partilhar esse mundo com outras pessoas; poder percebê-lo de distintas maneiras e de pontos de vistas inusitados. O que é gerado é uma potencialidade, é um ambiente e uma situação em potencial, na qual você vai encontrar ou não com outras pessoas, se integrar ou não a outras ações e performances ou vai ficar navegando, explorando e criando seus próprios percursos, nesse ambiente poético virtual partilhável. (PRADO, 2003a)

A utilização de ambientes multiusuário entre os artistas de arte mídia é cada vez mais recorrente: os artistas partem para a instauração de canais de interação entre as pessoas. Em 1998, Jeffrey Shaw, criador do pioneiro trabalho Legible Cities, desenvolve The Distributed Legible Cities, onde novamente o participante tem em seu poder uma bicicleta, em sua frente, o mundo virtual 3D e pode, ainda, encontrar outros usuários no espaço, visualizá-los através de uma representação gráfica e conversar entre si via voz. Assim como no caso de Desertesejo, não temos uma coletividade interagindo em tempo real diretamente com um software ou criando um trabalho coletivo como em Moone. A participação indivíduo-objeto - nos caminhos participativos da arte de Lígia Clark e Hélio Oiticica - passa a dar lugar também para a interação indivíduo-indivíduo, promovendo interfaces 
insólitas - artísticas - de contato humano, ou menos, de presença simultânea num mesmo espaço.

No vácuo social e ideológico da nossa contemporaneidade, a Realidade Virtual nos propõe novos espaços de expansão dos nossos limites. Os artistas dão forma a essas necessidades de partilha, de encontro com o outro, estabelecendo canais de contato. A existência pode ter os seus vazios preenchidos por esse imaginário habitável - que é a Internet - ou mesmo - nos caminhos que a ficção nos propõe - ser sumariamente substituída.

\section{REFERÊNCIAS BIBLIOGRÁFICAS}

COUCHOT, Edmond. A tecnologia na arte: da fotografia à realidade virtual. Tradução de Sandra Rey. Coleção Interfaces. Porto Alegre: Editora da UFRGS, 2003. DeLEUZE, Gilles; GUATTARI, Félix. Mil Platôs - Capitalismo e esquizofrenia. Vol.1. Tradução de Aurélio Guerra Neto e Célia Pinto Costa. Rio de Janeiro: Editora 34, 1995.

DOMINGUES, Diana. Criação e Interatividade na Cibearte. São Paulo: Editora Experimento, 2002.

FLORIDO, Janice (coord.). Platão. Coleção "Os pensadores". São Paulo: Editora Nova Cultural, 1999.

JABÈS, Edmond. Un étranger, avec, sous le bras, un livre de petit format. Paris: Editions Gallimard, 1989.

KERCKHOVE, Derrick de. A Realidade Virtual pode mudar a vida? In: DoMINGUES, Diana (org.) A arte no século XXI. São Paulo: Ed. Unesp, 1997. p. 49-51.

- O Senso Comum, antigo e novo. In: PARENTE, André (org.). Imagem Máquina. São Paulo: Ed.34,1993. p. 56-64.

PEARCE, Celia. The Interactive Book: A Guide to the Interactive Revolution. Indianapolis: Macmillan Technical Publishing, 1997.

PRADO, Gilbertto. Os sites de arte na rede Internet. Campinas: [s.n., 1997a].

- As Redes Artístico-Telemáticas : Novos territórios para o imaginário surgem com as máquinas de comunicação. In: REVISTA IMAGENS. n 3.Campinas: Ed. Unicamp, 1997b. p. 41-44. 
- Cronologia de Experiências Artísticas nas

Redes de Telecomunicações. Campinas: [s.n., 1997c].

- Desertesejo: um projeto artístico de ambiente virtual multiusuário na Internet. In: CADERNOS DA PÓSGRADUAÇÃO Vol.4, n.1. Campinas: Instituto de Artes/Unicamp,2000.p.40-53.

- Arte telemática: dos intercâmbios pontuais aos ambientes virtuais multiusuário. São Paulo: Itaú Cultural, $2003 a$.

- Experiências Artísticas em redes telemáticas. In: ARS - Revista do departamento de artes plásticas da ECA-USP. $N^{\circ} 1$. Vol. 1. São Paulo: USP, 2003b. p. 49-57.

1 Matrix. (The Matrix). EUA, 1999. Direção: Andy Wachowski, Larry Wachowski.

2 No filme, as duas realidades são concomitantes e perceptivamente semelhantes mas defende-se a idéia de que a realidade "real" - aquela na qual fisicamente existimos - é a ideal, numa busca pela "verdadeira" realidade.

3 Jogos eletrônicos por computador ou videogame.

4 A visão estereoscópica resume-se em um par de imagens em movimento ou estáticas, sendo que uma delas possui um pequeno deslocamento horizontal em relação à outra, que simula a distância interpupilar, ou seja, entre a pupila do olho esquerdo e a do olho direito. Esse efeito proporciona a impressão de profundidade.

5 Termo criado por Ivan Sutherland, que definia: "Realidade Virtual é um mundo simulado, gerado por computador, no qual o usuário pode navegar em tempo real como se estivesse movendo em um espaço tridimensional real" (PEARCE, 1997:105)

6 Desertesejo (http://www.itaucultural.org.br/desertesejo) é um projeto artístico de Gilbertto Prado desenvolvido no Programa Rumos Novas Mídias do Itaú Cultural, São Paulo, em 2000. Direção: Gilbertto Prado; Realização: Programa Rumos Itaú Cultural Novas Mídias; Produção:Flávia Gonsales; Modelagem 3D e VRML: Nelson Multari; Web design: Jader Rosa; Apoio: Minc/Intel - Pentium III.

7 o Projeto wAwRwT foi inicialmente desenvolvido no Laboratório Paulo Laurentiz do Instituto de Artes da Unicamp, em 1995, quando possua o sugestivo endereço: http://wawrwt.iar.unicamp.br. Em 2003, o projeto migra também para a Escola de Comunicação e Artes da USP, onde também está on-line através do endereço: http://www.cap.eca.usp.br/wawrwt . A atual formação do grupo coordenado por Gilbertto Prado, conta com Luisa Paraguai Donati, Edgar Franco e Fábio Oliveira Nunes.

8 Criado por Kit Galloway e Sherry Rabinowitz, o Eletronic Cafe teve sua primeira edição em 1984, em Los Angeles (EUA), sendo considerado o primeiro cibercafé do mundo. 
9 RSDI: Rede digital de serviços integrados. A conexão de Moone era realizada por um modem que transmitia $64 \mathrm{kbits} / \mathrm{s}$ via RSDI.

10 Open Studio (http://draw.artcontext.net/) desenvolvido por Andy Deck, foi antecedido por um projeto parecido - e mais conhecido - atualmente fora do ar: GhaphicJam.

11 Programa de navegação via Internet em mundos virtuais, disponível através do endereço: http://www.activeworlds.com.

12 Numa tradução literal: luva de dados. Dispositivo de ação em ambientes virtuais, projetado por Zimmerman em 1982 e desenvolvido em parceria com Lanier em 1987. Em 1989, surge a versão comercial deste dispositivo, para a utilização através de jogos eletrônicos.

13 Lanier, conhecido como um dos pioneiros na área, adotou o termo Realidade Virtual nos anos 70 para designar a imersão mediada por dispositivos, como o seu conhecido capacete, desenvolvido em de duas pequenas telas de vídeo - uma para cada olho - e fones de som estéreo.

14 CAVE (Cave Automated Virtual Reality Environment/Ambiente de caverna automatizado para realidade virtual) ou caverna, em português, consiste em uma sala em que paredes, teto e chão são telas semi-transparentes aonde as imagens são projetadas, permitindo que uma ou mais pessoas fiquem imersas no ambiente virtual. A projeção das imagens é feita por projetores posicionados atrás das telas e pode ser estereoscópica, exigindo dos usuários o uso de óculos obturadores.

15 A empresa homônima do famoso videogame doméstico, Atari, foi criada em 1972 por Nolan Bushnell. Dois anos mais tarde, foi lançado o "Pong", um game imbutido no console da máquina, vendido nos EUA em lojas de departamento,> >que foi um sucesso na época. No Brasil, o sucesso ocorreu a partir de 1982, com a versão 2600 do videogame, que se tornou sinônimo de entretenimento eletrônico.

16 Antes da Internet, ainda que de maneira mais contida, popularizam-se as BBS - Bulletin Board System - onde através de um terminal conectado via linha telefônica era possível acessar um banco de serviços interativos e também o Videotexto (originado no sistema Minitel francês).

17 World Wide Web: criada por Tim Berners-Lee, no início dos anos 90, trata-se da interface gráfica da Internet, popularizada pelos web sites, onde é possível a transferência de imagens, sons, textos pela rede, bem como, a criação de vínculos entre os documentos.

18 HTML: Hipertext Markup Language; Linguagem de criação de páginas na Internet.

19 DELEUZE e GUATTARI (1995:18) :"Um rizoma pode ser rompido, quebrado em um lugar qualquer, e também retoma segundo uma ou outra de suas linhas e segundo outras linhas. É impossível exterminar as formigas, porque elas formam um rizoma animal do qual a maior parte pode ser destruída sem que ele deixe de se reconstruir. Todo rizoma compreende linhas de segmentaridade segundo as quais ele é estratificado, territorializado, organizado, significado, atribuído, etc; mas compreende também linhas de desterritorialização pelas quais ele foge sem parar." Conceito que juntase a Internet para explicar o seu caráter regenerativo. Cada ponto da rede pode originar um novo ponto, e assim cresce, sem limitações. 
20 Um browser 3D funciona como um plug-in, em conjunto com o navegador web. Ao se deparar com arquivos com a terminação WRL, o navegador passa a exibir os conteúdos através de sua janela, como uma página HTML. Entre os navegadores VRML mais conhecidos estão o Cosmo Player, Blaxxun, Real Space, Cortona, entre outros.

21 http: //www. web3dart.org

22 É bom lembrar que para a visualização deste trabalho desenvolvido em VRML é necessário possuir um navegador específico para ambientes virtuais em 3D na Internet. Para este trabalho, aconselha-se utilizar o plug-in Blaxxun, disponível em: http://www.blaxxun.com/services/support/download/

23 Nota da autora: A imagem poética contemporânea foi o título de um curso realizado por Ligia Cademortoni na Universidade de Caxias do Sul, Brasil, 1992. Foram analisados filmes nos quais a imagem do deserto é usada abundantemente: Telma e Louise, Badgá Cafe, Paris Texas, Profissão Repórter, o céu que nos protege, entre outros, nos quais é explorada a metáfora do deserto.

24 A ordem dos ambientes, colocada anteriormente - em semelhança a ordem proposta pelo artista - é somente com o intuito de enumerar as situações: para visualizar o mundo Plumas por exemplo, não é necessário passar pelo Viridis. Assim como é possível ver Viridis após ter navegado em Plumas. Somente a passagem pelo ambiente Ouro é inevitável para ver o trabalho.

25 Viridis é um termo grego usado para designar a cor do céu e a cor do mar e a junção de ambos no horizonte. Isso explica, de certo modo, a aparência do ambiente: metade mar, metade céu.

26 Através de um mecanismo em CGI, o servidor do site identifica o número I.P. (Internet Protocol) que por sua vez, indica qual a origem do computador cliente - do visitante - e seu respectivo fuso horário.

27 Em 1998, 9/4 Fragmentos de Azul foi apresentado na II Bienal do Mercosul, em Porto Alegre.

28 Numa tradução literal: 0 azul do céu.

29 Numa tradução literal : o dia e a noite.

30 Primeiro sistema de conversas em tempo real na rede Internet, o IRC é anterior ao advento da própria World Wide Web. Foi criado por Jarkko Oikarinen, em 1988, existindo através de inúmeros canais em servidores específicos para este objetivo. Normalmente cada canal, possui um agente - artificial ou humano - que monitora e desconecta usuários mal intencionados ou pouco agradáveis. Os canais de IRC abrigam diversas comunidades virtuais fundadas em interesses comuns.

31 sites portais: sites da web que reúnem um enorme número de serviços e conteúdos diferentes (entretenimento, jornalismo, sites pessoais, vídeos etc) num mesmo espaço. 